\title{
Strategies and mitigation devices in the speech act of disagreement in American English
}

\section{Hassen Khammari*}

Department of English, the Faculty of Letters, Arts \& Humanities, University of Manouba, Tunisia.

\begin{tabular}{llllll}
\hline Received: 21.05.2021 & • & Accepted: 19.06.2021 & • & Published: 30.06.2021 & • Final Version: 30.06.2021 \\
\hline
\end{tabular}

\begin{abstract}
The present study aimed at exploring the strategies of disagreement and hedging devices used by native speakers of English. The study elicited the informants' reactions when disagreeing with higher, equal, and lower status. The responses were analyzed using Brown and Levinson's (1987) politeness model and Hyland's (1998) hedging taxonomy. Discourse completion test data was analyzed both quantitatively and qualitatively. The findings revealed that native speakers of American English used positive politeness strategies considerably with higher and equal status interlocutors (father, teacher, and friends). The respondents were concerned with saving their interlocutors' positive face regardless of their social distance and power. The only significant difference, in terms of strategy selection, was identified in highly face-threatening contexts (accusation), where the informants opted for bald on record politeness strategies because of the seriousness of the interlocutor's (supervisor) claims (plagiarism). The data showed also that native speakers relied on hedges considerably to mitigate their disagreements.
\end{abstract}

Keywords: Face-threatening acts, disagreement, politeness, mitigation, hedges, boosters, contextual factors.

\section{Introduction}

Traditionally, a native speaker's knowledge of his mother tongue was confined to acquiring the grammar and vocabulary of the language or what is referred to as grammatical competence. Thanks to this competence, the native speaker successfully produces infinite sentences. Moreover, s/he can tell what is grammatical and what is ungrammatical. However, a crucial question was left unanswered: how could we use language appropriately in different contexts? The answer has been proposed by Hymes (1972), who -in addition to grammatical competence- has recognized the existence of a communicative competence which echoes a more dynamic facet of language and language acquisition and addresses the question of appropriateness (of meaning and form).

The shift of interest from grammatical competence to sociolinguistic and pragmatic competence has not been ad-hoc. It has been rather dictated by the serious trouble speakers of a foreign language encounter due to the lack of sociolinguistic and cultural awareness that most often results in pragmatic failure. The acquisition of socio-cultural rules is crucial to language learners.

The realization of any speech act is governed by the norms of different speech communities (LoCostro, 1986, p.1) and dependent of established different cultural values and cultural priorities (Wierzbicka, 1991). Speech acts and especially face-threatening speech acts (FTAs) cannot be studied in isolation from contextual factors (e.g., Social Power, Social Distance, and Degree of

\footnotetext{
Corresponding Author: hassenkh08@live.fr
} 
Imposition) (Mey, 1993). FTAs challenge the face wants of an interlocutor (Brown \& Levinson, 1987) and their communication requires more attention from the speaker due to their potential undesirable effects on the hearer. This study investigates the speech act of disagreement and elicits the strategies and mitigation devices used to perform it.

\section{Literature review}

\subsection{Speech act theory}

Speech act theory represents an important subfield of pragmatics. The study of language use in context (pragmatics) requires the researcher to take into consideration the interactant's contribution to interaction (speech act). Speech act theory as initiated by Austin (1962) and developed by Searle (1969) posits that when people converse, they use grammatical and lexical units to produce utterances and more importantly to perform actions (Yule, 1996). These actions are considered "the basic or minimal units of linguistic communication (Searle, 1969, p. 16). In saying something, the speaker does something (Austin, 1962). By saying "I disagree", the speaker does not only produce an utterance in English but also performs an act, that of disagreeing. Compliment, request, apology, and disagreement are examples of speech acts. An utterance produced by a speaker has a communicative load to be inferred and interpreted by the hearer. Austin (1962) distinguishes three types of acts:

a) A locutionary act which stands for the fact of producing a meaningful utterance.

b) An illocutionary act which is the social function of the utterance.

c) A perlocutionary act which refers to the effect of the illocutionary act on the hearer. It depends on the context of the utterance and it is unpredictable (Mey, 1993, p. 112).

The illocutionary act appears to be the most frequently referred to and discussed. An illocutionary act is "the basic unit of human linguistic communication" (Searle, 1976, p. 1). Speech act theory has focused on the illocutionary force of an utterance to the extent that the term speech act has often been used to mean illocutionary act (Bach \& Harnish, 1979). The present study investigates the speech act of disagreement, which is a face-threatening act in Brown and Levinson's (1987) model.

\subsection{Disagreement}

In Austin (1962) classification, disagreement is a commissive speech act since it suggests a speaker's commitment to their ideas or beliefs. In Searle (1976) taxonomy, disagreement is a representative act since it is concerned with the speaker's commitment to the truth of the utterance. Fraser (1975, p. 192) classifies disagreement as an act of asserting because it is concerned with the appropriateness/ truthfulness of a prior proposition. In Leech (1983, p.104) illocutionary classification, disagreement is a conflictive act because it might result in social disharmony between speakers. From a politeness perspective (Brown \& Levinson, 1978), disagreement is a face threatening act (FTA). This means that "a speaker says something that represents a threat to another individual's expectations regarding self-image" (Yule, 1996, p. 61). The status of disagreement is not straightforward, which is a good reason to study it.

Disagreement may be subject to cultural variation. Numerous studies have shown that disagreement is a preferred speech act (Kakava, 2002; Blum-Kulka et al., 2002). In fact, preference depends on the context and the culture involved. Blum-Kulka et al. (2002) studied Jewish culture and found that it favors not only disagreement over agreement but unmitigated and unprefaced forms 
of it. The Jewish culture belongs to the group of cultures which display a preference for direct confrontational modes of disagreement they claim. This tendency seems to be common in the Greek culture (Kakava, 2002) and the Turkish culture (Dogancay-Altuna \& Kamisli, 1996).

Interactants might resort to politeness strategies to redress the face threatening act. Brown and Levinson (1987) propose four main strategies for politeness: (1) Bald on record which might result in the hearer's shock or embarrassment "clean your room"; (2) Positive politeness which helps minimize the threat to the hearer "I know you've been busy lately but could you clean the room"; (3) Negative politeness which engenders some degree of imposition on the hearer "I'm looking for money!"; and (4) the Indirect strategy which employs indirect language to soften or avoid imposition "it's getting hot here".

Brown and Levinson claim that all cultures perform politeness the same way- a position which has been criticized by many researchers (Wierzbicka, 1985; Held, 1989), who have attempted to show the shortcomings of the theory and call for adjustment. While Brown and Levinson suggest that being more direct is being less polite, some languages, like Chinese (Yu, 1999), French (Held 1989), and Polish (Wierzbicka, 1985), challenge this equation.

Brown and Levinson's theory has also been criticized for what constitutes face threats (Hernandez-Flores, 1999; Wilson, 1999). Sifianou (1992) criticizes Brown and Levinson's universality claims by showing that the Greek concepts of politeness emphasize warmth and intimacy. Unlikely, the American use of politeness implies consideration for the person.

In the area of speech acts, it is suggested (Brown and Levinson, 1987) that the patterns for realizing speech acts are identical across cultures and languages. Nevertheless, it is claimed that speech acts production varies cross-culturally (Wierzbicka 1991). Wierzbicka (1991) maintains that any claim to universality is basically manipulated by a western ethnocentric behavior. Laabidi and Bousfiha (2020, p.148) investigated the speech act of complaining as used by Moroccan EFL students. They found that context, interlocutors, and other socio-cultural variables influence the speakers' choice of complaining strategies.

To minimize the potential threat, the speaker can use face saving expressions or what Hyland (1998) calls hedges. Hedges play the role of softening devices that reduce the undesirable effect of the utterance on the hearer.

\subsection{Hedges and Boosters}

Hedges are words "whose job is to make things fuzzier or less fuzzy" (Lakoff, 1973). They are used to reduce the speaker's commitment to their claims. Hedges may reduce the force of face-threatening speech acts. They may function as tools to avoid criticism (Crystal, 1988). They play the role of a ritual function acting as disfluencies in smoothing over a disagreement with a partner (Hatch, 1992, p. 127). Hedges can be better understood from 'Appraisal Theory' (Iedema et al., 1993; Martin \& White, 2005). This theory views discourse as units conveying positive or negative assessments. The directness of the utterance can be strengthened or weakened. The speaker or the writer conveys their involvement in the text by adopting stances either toward phenomena (entities, happenings, and state of affairs) or toward metaphenomena (propositions about the entities, the happenings and the state of affairs) (White, 2015, p.1). A central notion in Appraisal theory is that speakers of a language use evaluative resources to negotiate social relationships, by telling listeners or readers how we feel about things and people (Martin \& Rose, 2003, p. 19). Hyland (2002, p. 349) asserts hedges and boosters "are communicative strategies for increasing or reducing the force of statements. Their importance in academic discourse lies in their contribution to an appropriate rhetorical and 
interactive tenor, conveying both epistemic and affective meanings." Hedges carry both the speaker's or writer's confidence in the truthfulness of a proposition and an attitude to the hearer or reader (Hyland, 2002, p. 350).

Hedges help to "demonstrate personal honesty and integrity through willingness to address hard realities, albeit behind a shield of mitigation" (Hyland, 1998, p. 238). Mitigation is not considered "a particular type of speech act but as the modification of a speech act: the reduction of certain unwelcome effects which a speech act has on the hearer" (Fraser, 1980, p. 341).

Brown and Levinson's (1987) model of politeness strategies and Hyland's (2002) categorization of hedges and boosters will be used to analyze the data both qualitatively and quantitatively.

\section{3. Materials and Methods}

\subsection{Instrument(s)}

The present study relied on discourse completion tests to elicit disagreement strategies and patterns in American English. Discourse completion tests (DCTs) have been widely used in cross-cultural and interlanguage pragmatics (Kasper \& Dahl, 1991). They allow the researcher, through controlling contextual factors, to study how language varies among learners. DCTs have been extensively used in the study of speech acts (e.g., Olshtain \& Cohen, 1983; Beebe \& Cummings, 1985; Blum-Kulka et al., 1989; Hartford \& Bradovi-Harlig, 1992).The interest in the use of DCTS stems from the advantages they have. Most importantly, they are convenient, in the sense that they make it possible for the researcher to collect a large amount of data (Hartford \& Bradovi-Harlig, 1992, p.33). They allow the researcher to manipulate and control variables, which makes it easier to compare the realization of speech acts across languages (Beebe \& Cummings, 1985).

The disagreement situations were varied systematically according to the informants' social power, social distance and severity of offense. It has been shown that the aforementioned variables are of great significance in determining speech act behavior in cross cultural pragmatics (Beebe \& Takahashi, 1989; Blum-Kulka et al., 1989; Brown \& Levinson, 1987). Social power refers to the power of the speaker over the hearer. The speaker could have more power than the hearer $(+\mathrm{P})$, the speaker and the hearer could have equal power $(=\mathrm{P})$, or the speaker could have less power than the hearer $(-\mathrm{P})$. Social distance refers to the degree of familiarly between the interlocutors: the interlocutors either are familiar to each other $(-D)$ or do not know each other $(+D)$.

\subsection{Participants}

Thirty native speakers of American English participated in this study. The informants' age ranged from 18 to 22 years. They consisted of undergraduate university students, who were asked to fill out the DCT (See Appendix I).

\subsection{Research Questions}

What are the disagreement strategies and mitigation devices used in American English? How do the variables of social distance and social power affect the informants' choice of disagreement categories? 


\section{Results and Discussion}

\subsection{Disagreement Strategies and hedges in American English}

The strategies of disagreement identified in the data were analyzed based on Brown and Levinson's (1987) politeness strategies model, which is still useful and applicable in the study of communication and speech acts. Recently, Pham and Yeh (2020) have studied politeness of Vietnamese students and used Brown and Levinson's (1987) super strategies to investigate the strategies used when writing request email in English.

\section{The strategies of disagreement}

\section{a. . Bald on record strategies}

Bald on record strategies are direct ways of saying things, without any minimization to the imposition, in a direct, clear, unambiguous and concise way (Brown and Levinson, 1987). As figure 1 displays, NSE frequently employed 'direct refusal' while 'reminder', 'protest' and 'challenge' were among the least frequently used strategies.

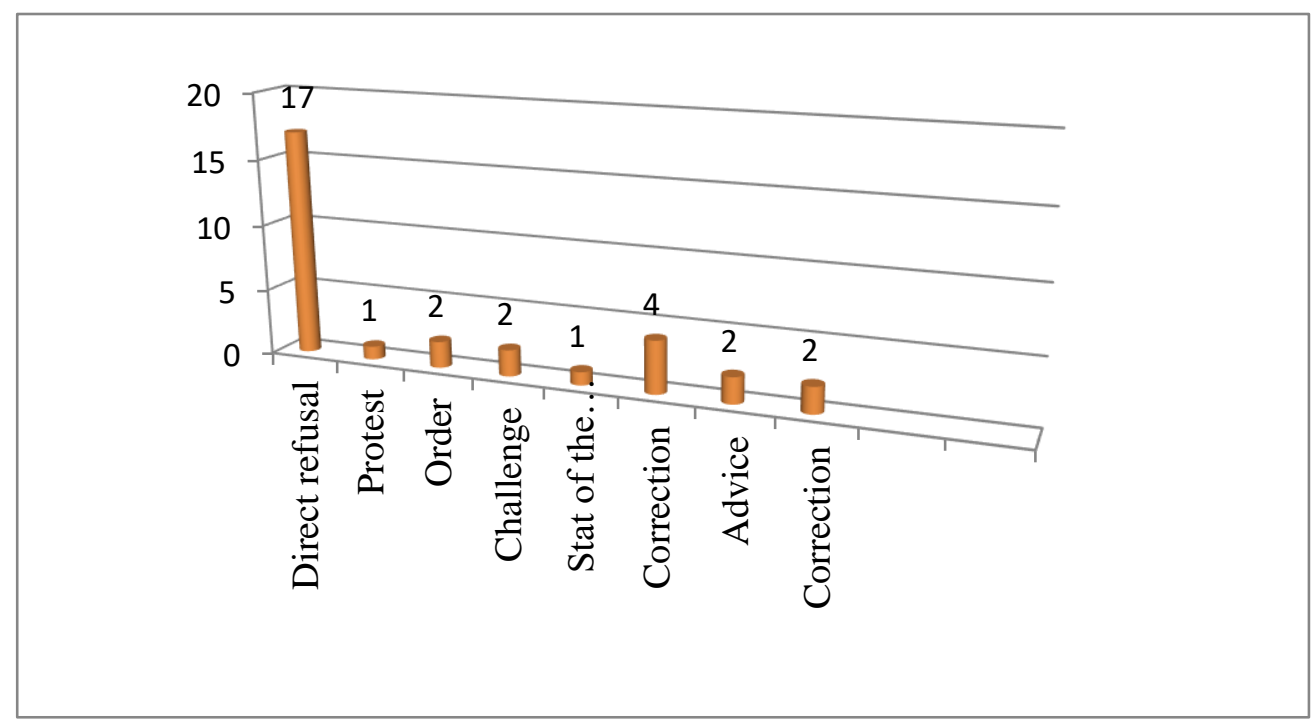

Figure 1. Bald on record politeness strategies (\%)

\section{Direct refusal}

e.g., 1. I'm sorry to tell you we are taking the wrong turn. (Situation 7)

NSE did not opt for direct refusal very frequently and they mitigated their utterances to avoid creating a feeling of discomfort on the hearer.

\section{Protest}

e.g., 2. Look. You're kind of hitting a nerve here! (Situation 10)

NSE used this strategy mainly in situation (10) (plagiarism). Resorting to this strategy might be explained by the seriousness of the accusation uttered by the supervisor.

\section{Statement of the blunt opposite}

Several instances of this strategy were identified in the data.

e.g., 3. Or, maybe being in a relationship could be a help. (Situation 4)

\section{Correction}

e.g., 4. Actually, I think the airport is a little further down. (Situation 7) 
Correction was used to disagree with a high-status interlocutor, i.e., a teacher Advice

NSE used Advice considerably when addressing a teacher (Situation 7). They used the inclusive 'we' to provide advice. This pattern was not found when the speaker addressed a friend. This might be explained by the fact that advice is not welcomed by the interlocutor because it embodies an imposition upon his/her freedom of action. Thus, using the inclusive 'we' redresses the illocutionary force of the statement addressed to the teacher.

e.g. 5. I think we should go farther. (Situation 7) (Teacher)

The speaker "call [s] upon the cooperative assumptions and thereby redress [es] the FTA" (Brown \& Levinson, 1987, p. 127). With friends, advice was rather more direct. The following examples illustrate this pattern.

\section{b. Positive Politeness}

Brown and Levinson (1987) affirm that positive politeness strategy attempts to attend the hearer's interest, wants, and goods. Figure 2 shows the distribution of positive politeness strategies identified in the data.

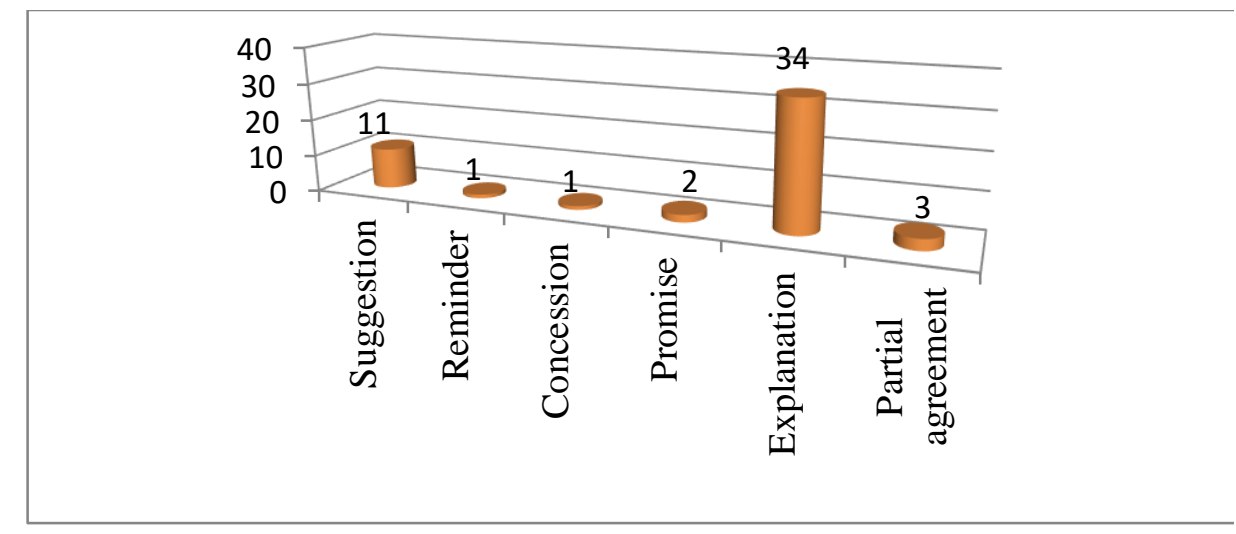

Figure 2. Positive politeness strategies (\%)

The positive politeness strategies employed by the informants are listed below.

\section{Suggestion}

Suggestion was frequently used by NSE.

e.g., 6. What about a trip to the beach instead? (Situation 2)

Partial agreement

This strategy is used to delay or weaken disagreement. Partial agreement was frequently used by NSE (27 occurrences). Classified as a positive remark, partial agreement is very important to preface face-threatening acts in English (Takahashi \&Beebe, 1993).

e.g., 7. That's a great topic too but ... (Situation 9)

\section{Promise}

NSE frequently used this strategy in situation 6 (camping) where they were expected to disagree with their father.

e.g., 8. I have already agreed to go and I promise that I will be safe and I will have my phone with me the whole time in case of an emergency (Situation 6) 
Promises "demonstrate S's [speaker] good intentions in satisfying H's [hearer] positive-face wants" (Brown \& Levinson, 1978, p. 125).

Explanation

Explanation was among the strategies most frequently used in the data.

e.g., 9. You know, I bought a Dell and it had a defective hard drive. And Dell would not let me use the warranty. (Situation 5)

Explanation reduces the face-threatening load of the utterance and gives the hearer an detailed and clearer account of the situation.

c. Negative politeness

According to Brown and Levinson (1987, p.129) negative politeness is "the heart of respect behavior".

The negative politeness strategies identified in the data are displayed in Figure 3.

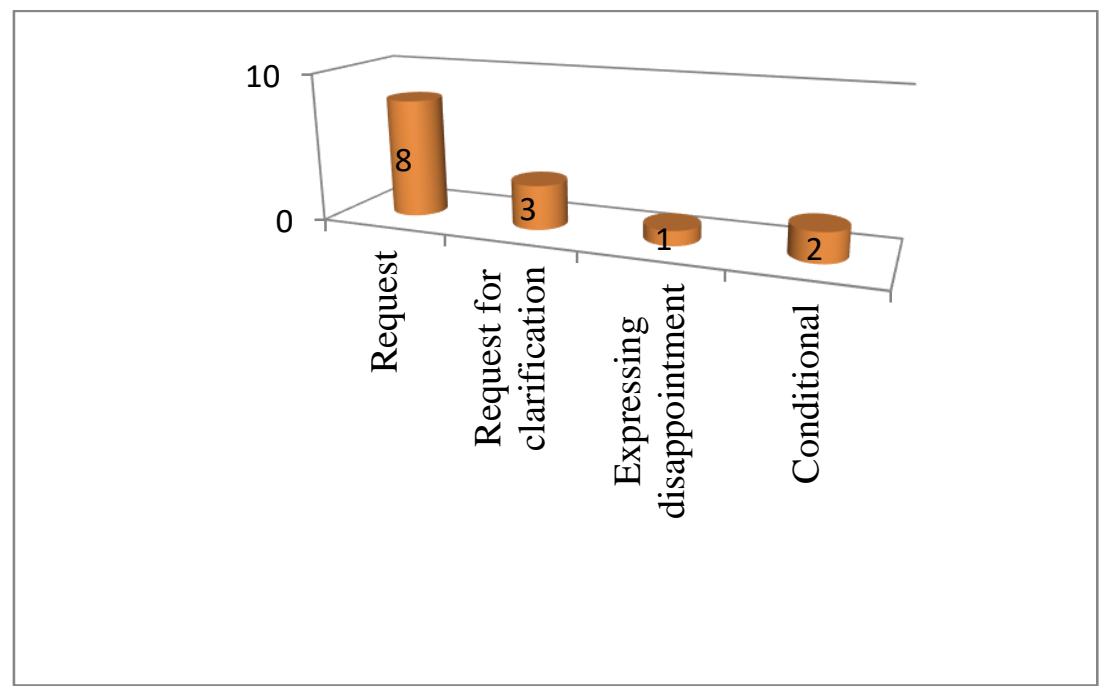

Figure 3. Negative politeness strategies (\%)

\section{Request}

e.g., 10. This is unfair dad, I gave my word? (Situation 6)

NSE used Request 69 times ( $8 \%$ ). The informants used this negative politeness strategy to redress the directness of their utterances.

\section{Conditional}

This strategy is among the least frequently used disagreement strategies.

e.g. 11. If you are busy now, I completely understand. (Situation 8)

In example 11, the speaker seemed much more interested in making the teacher feel comfortable and at ease, although the teacher was responsible for the delay. Such a tendency shows the speakers' concern about saving the interlocutor's face and disagreeing non-overtly.

\section{d. Off record strategies}

Off-record strategies are mainly indirect strategies, where the speaker avoids the imposition on the hearer. Off record strategies were the least frequently used strategies to perform disagreement. 


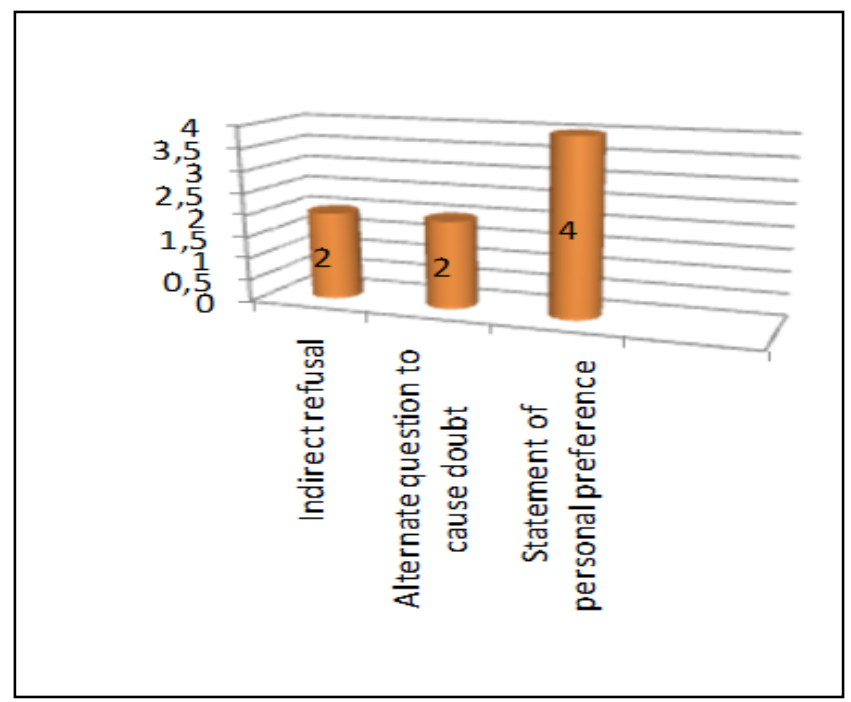

Figure 4. Off record politeness strategies (\%)

\section{Indirect refusal}

Indirect refusal is an avoidance strategy. It accounts for $2 \%$ of the total number of responses provided.

e.g., 12. Wow. That's a really interesting topic but I'm not very familiar with it at all. (Situation 9)

The speaker distances him/herself from the suggested topic although s/he expressed appreciation in the beginning.

\section{Alternate question to cause doubt}

NSE used this strategy mainly in situations 1 (unfashionable shoes) and 8 (meeting with teacher). e.g., 13. The question is can you walk comfortably in them? (Situation 1)

This strategy is an invitation from the speaker to the hearer to reconsider his/her position or opinion. Alternate questions have a psychological effect in the sense that they 'shake' the hearer's assumptions.

\section{Statement of personal preference}

This strategy was not reported by the previous studies on disagreement. e.g., 14. I would never buy a pair of shoes that isn't comfortable. (Situation 1)

This strategy allowed the speaker to express disagreement by stating what s/he would do as opposed to telling the interlocutor what to do.

\subsection{Hedges and boosters}

Inspired by Hyland's study on hedges and boosters (2005), the following section introduces the most frequent linguistic devices used to "soften" or "aggravate" the speech act of disagreement in the four distance situations.

\section{a. Hedges and Boosters in distance situations}

Inspired by Hyland's study on Hedges and Boosters (2005), the following section introduces the most frequent linguistic devices used to "soften" or "aggravate" the speech act of disagreement in the four Distance situations.

The analysis of the data (Table 1) revealed that NSE used hedges more frequently than Boosters (55 vs. 29 occurrences). Boosters, however, exceeded Hedges in NNSE data (22 vs. 10 occurrences). 
Situations 1 (unfashionable shoes) and 4 (clerk promoting a computer) elicited the highest frequencies of Hedges ( 30 and 18 occurrences). In these situations, the informants did not opt for high levels of directness when they performed disagreement, which could explain the significant use of hedges. There seems to be an association between NSE production of less direct strategies in situations 1 and 4 and the high frequencies of hedges produced.

Table 1. Distribution of Hedges and Boosters (Distance)

\begin{tabular}{ccc}
\hline Situation & $\begin{array}{c}\text { Hedges } \\
(\mathbf{5 5 / 8 4 )} \\
\mathbf{N}^{\circ}\end{array}$ & $\begin{array}{c}\text { Boosters } \\
(\mathbf{2 9 / 8 4 )}\end{array}$ \\
\hline Nituation $\mathbf{1}$ & $\mathbf{3 0}$ & 9 \\
\hline Situation 2 & 3 & 4 \\
Situation 3 & 4 & 8 \\
Situation 4 & $\mathbf{1 8}$ & 8 \\
\hline
\end{tabular}

NSE used a variety of Hedges and Boosters to either mitigate or aggravate disagreement (See Appendix II). The hedges identified were tentative verbs and modals (seem, look, may, would, and could), Tentative adjectives/adverbs (probably and maybe), conditional, reluctance markers (I don't know, are you sure?), apology, and empathy. NSE used different boosters such as modals (have to, should, and will), adjectives and adverbs (extremely, totally, really, absolutely, and completely). In NSE data, a frequent use of hedges in Situation 1 (unfashionable shoes) was observed (30 occurrences), which reflects the speakers' awareness that their disagreement, with a friend about shopping choices, requires mitigation to reduce any possible undesirable effects on the interlocutors' relationship. NSE also employed hedges frequently in Situation 4 (clerk promoting a computer) (18 occurrences). The wide distance relationship between the speaker and the hearer might explain the high number of hedges used in this situation.

\section{b. Hedges and Boosters in Power situations}

The social status of the interlocutor has an effect on the choice and frequency of Hedges and Boosters used either to 'soften' or 'aggravate' disagreement. The following section deals with the Hedges and Boosters identified in the second set of situations (Power) and their importance of communicating politeness levels between interlocutors.

Table 2. Distribution of Hedges and Boosters (Power)

\begin{tabular}{ccc}
\hline Situation & $\begin{array}{c}\text { Hedges } \\
(\mathbf{1 0 2 / 1 7 1 )} \\
\mathbf{N}^{\circ}\end{array}$ & $\begin{array}{c}\text { Boosters } \\
(\mathbf{6 9 / 1 7 1 )}\end{array}$ \\
\hline Situation 5 & 20 & 22 \\
\hline Situation 6 & 43 & 15 \\
\hline Situation 7 & 21 & 18 \\
\hline Situation 8 & 18 & 14 \\
\hline
\end{tabular}


The investigation of the data revealed that NSE used diverse forms of hedges and boosters to either mitigate or strengthen their disagreements. The hedges identified were tentative verbs and modals (would, could, and may), tentative adjectives or adverbs (maybe, perhaps, and probably), conditionals, apology expressions (sorry, excuse me, and I beg your pardon). Boosters include verbs and modals (have to, will, should), adjectives and adverbs (sure, certain, certainly, truly, really, and entirely).

1. The effect of contextual factors on the production of disagreement

The section below sheds light on the effect of the contextual factors of Distance and Power on NSE performance of the speech act of disagreement.

\section{a. Social Distance}

In situation 5 (clerk promoting a computer, + distance), NSE used positive politeness strategies considerably $(19 \%)$.

Situation 3 (the republic of Ireland) made an exception in that bald on-record strategies were used frequently (49\%). The classroom setting gave the informants an 'academic legitimacy' to use baldon record strategies. Direct disagreements are expected and even appreciated in academic settings and they are part of the learning process (Rees-Miller, 2000). NSE used hedges to mitigate the directness of their disagreements regardless of the addressee's un/familiarity. This is reflected in the utterances below.

e.g., 15. -I think you might be confused a bit because it is actually a sovereign nation. (Situation 3) (Friend)

-Listen, I hate to disagree with you, but I recently bought one of these - not from this store - and I have had a lot of trouble with it. (Situation 5) (Stranger)

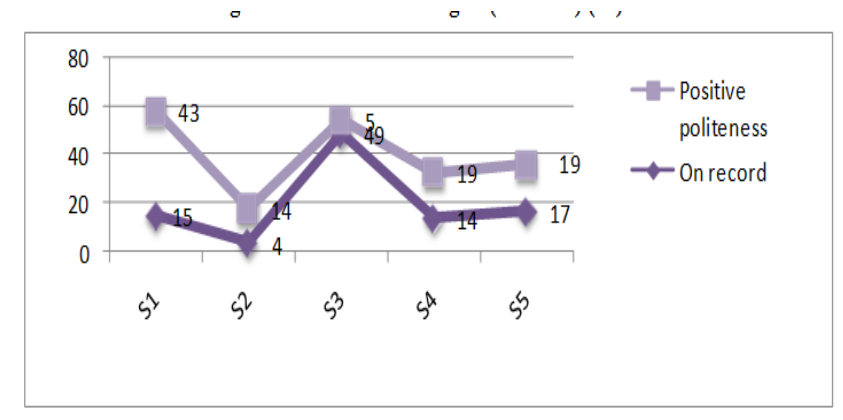

Figure 5. Politeness Strategies (Distance) $(\%)$

As example 15 shows, NSE used hedges like 'I think', 'bit', and 'actually' and mitigating expressions like 'I hate to disagree with you' and 'not from this store' to soften disagreements.

\section{b. Social Power}

Figure 6 shows that NSE used positive politeness strategies frequently (26\%). NSE were interested in establishing a positive relationship with the interlocutor to make their plans understood and eventually approved by the other party (father). There seems to be a familiarity between parents and their children in the American culture manifested through the use of positive politeness strategies. 


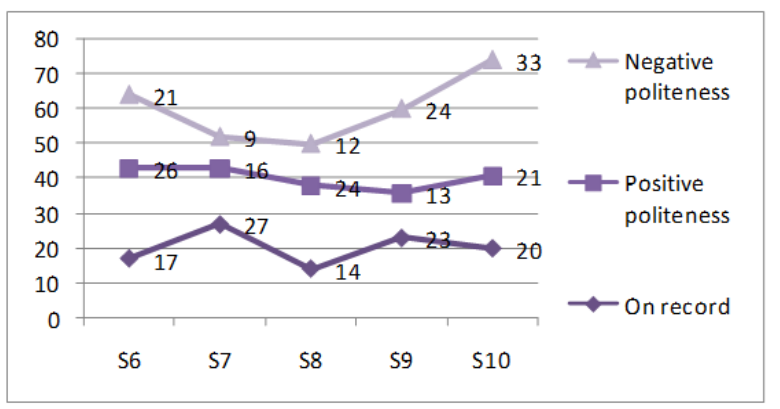

Figure 6. Politeness Strategies (Power) $(\%)$

Situation 7 (the way to the airport) elicited 27 instances of bald on-record strategies (27\%). The informants employed mitigating devices frequently to soften the effect of the disagreement act on the interlocutor.

e.g., 16. I think it's the turn up ahead. I remember because when I came last week the turn was right after that big shiny office building. (Situation 7)

To address a high-status friendly addressee in situation 8 (meeting with the teacher), the informants used positive politeness strategies ( $24 \%$ ). However in situation 9 (alternate topic), where the addresser (student) and the addressee (teacher) do not share a friendly relationship, the informants used negative politeness strategies to disagree and minimize the imposing load of the disagreement.

In situation 10 (plagiarism), NSE frequently used negative politeness strategies (33\%) to disagree with the interlocutor's accusation (plagiarism) because the addressee is still a teacher (high-status).

\section{Conclusion}

NSE used a variety of strategies to perform disagreement (e.g. 'direct refusal', 'accusation', 'alternate question to cause doubt', 'statement of personal preference). With regard to the linguistic markers used to soften or aggravate disagreement, NSE employed hedges more frequently than boosters. The informants used positive politeness strategies considerably, which are generally used among intimates. This choice portrays the relationship between parents and their son(s)/daughter(s) in the American culture. When adolescents reach their twenties (the age of the informants of the present study), they are treated as friends and they are encouraged to express their opinions freely and openly.

In the same vein, the asymmetrical relationship teacher-student, where the teacher has power over the student, more indirect disagreement strategies are expected. The findings showed that NSE opted for positive politeness strategies to perform disagreement with a $-\mathrm{D}$ teacher and negative politeness strategies to disagree with $\mathrm{a}+\mathrm{D}$ teacher. The more distant the relationship is, the more indirect disagreement strategies are. The severity of the teacher's accusation (plagiarism) might explain NSE frequent use of bald on-record and positive politeness strategies. The more serious the offence is, the more direct strategies are.

Based on these findings, the American culture seems to favor direct strategies to disagree with high power interlocutors (father, teacher) without affecting the asymmetrical relationships. The informants do not mind performing face-threatening acts while expressing themselves for the sake of clarity and self-defense, which is a characteristic of low power distance cultures. Native speakers, however, relied on hedges considerably to smooth the speech act of disagreement. 


\section{References}

[1] Austin, J. (1962). How to Do Things with Words. Oxford: Oxford University Press.

[2] Bach, K. and Harnish, R. M. (1979). Linguistic Communication and Speech Acts. Cambridge, Massachusetts, and London: MIT Press.

[3] Beebe, L. M., and Takahashi, T. (1989). Sociolinguistic Variation in Face-threatening Speech acts: Chastisement and disagreement. In M. Eisenstein (Ed.), The Dynamic Interlanguage: Empirical Studies in Second Language Variation. New York: Plenum.

[4] Beebe, L. M., and Cummings, M. C. (1985). Speech Act Performance: A Function of the Data Collection Procedure? [Paper presentation]. TESOL Convention, New York.

[5] Blum-Kulka, S., Blondheim, M., and Hacohen, G. (2002). Traditions of Dispute: from Negotiations of Talmudic Texts to the Arena of Political Discourse in the Media. Journal of Pragmatic, 34, (10-11), 1569-1594.

[6] Blum-Kulka, S., House, J., and Kasper, G. (1989). Cross-cultural Pragmatics: Requests and Apologies. Norwood, NJ: Alblex Publishing Corporation.

[7] Brown, P., and Levinson, S. C. (1987). Politeness: Some Universals in Language Use.Cambridge: Cambridge University Press.

[8] Crystal, D. (1988). On keeping one's hedges in order. English Today, 15, 46-47.

[9] Dogancay-Aktuna, S., and Kamisli, S. (1996). Discourse of Power and Politeness through the Act of Disagreement [Paper Presentation] at the Annual Meeting of the American Association for Applied Linguistics, Chicago, Illinois.

[10] Fraser, B. (1975). Hedged performatives. In Cole, P. and Morgan, J. L. (Eds.). Syntax and Semantics (pp. 187-210). New York: Academic Press.

[11] Fraser, B (1980). Conversational mitigation. Journal of Pragmatics, 4 (4), 341-350

[12] Hartford, B. and Bardovi-Harlig, K. (1992) Experimental and Observational Data in the Study of Interlanguage Pragmatics. Pragmatics and Language Learning, 3, 33-52.

[13] Held, G. (1989). On the role of maximization in verbal politeness. Multilingua, 8, 167-206.

[14] Hernandez Flores, N. (1999). Politeness ideology in Spanish colloquial conversations: the case of advice. Pragmatics, 9(1), 37-50.

[15] Hyland, K. (2005). Metadiscourse. London: Continuum.

[16] _ (2002). Directives: Argument and Engagement in Academic Writing. Applied Linguistics, $23(2), 215-239$.

[17] _ _ (1998). Hedging in Scientific Research Articles. Amsterdam: John Benjamins.

[18] Hatch, E. 1992. Discourse and Language Education. Cambridge: Cambridge University Press.

[19] Hymes, D. (1974). Foundations of Sociolinguistics: An Ethnographic Approach. Philadelphia: University of Pennsylvania.

[20] Iedema, R., Feez, S., and White, P. R. R. (1993). Media literacy, Disadvantaged Schools Program. Sydney: NSW Department of School Education.

[21] Kakava, C. (2002). Opposition in Modern Greek Discourse: Cultural and Contextual Constraints. Journal of Pragmatics, 34, 1537-1568.

[22] Kasper, G. and Dahl, M. (1991). Research Methods in Interlanguage Pragmatics. Studies in Second Language Acquisition, 13 (2), 215-247.

[23] Laabidi, A., and Bousfiha, A. (2020). Speech Act of Complaining: Socio-Pragmatic study of Complaint by Moroccan EFL Learners. International Journal of Language and Literary Studies, 2(2), 148-155. https://doi.org/10.36892/ijlls.v2i2.294

[24] Lakoff, G. (1973). Hedges: a study in meaning criteria and the logic of fuzzy concepts. Journal of Philosophical Logic, 2 (4), 458-508.

[25] Leech, G. N. (1983). Principles of Pragmatics. London: Longman

[26] LoCastro, V. (1986). Yes, I agree with you, but: Agreement and Disagreement in Japanese and American English [Paper Presentation.] The Japan Association of Language Teachers' International Conference on Language Teaching and Learning, Hamamatsu, Japan. Locher, M. A. (2004). Power and Politeness in Action. Disagreements in Oral Communication. Berlin: Mouton de Gruyter.

[27] Martin, J.R. and White, P.R.R. (2005).The language of evaluation: Appraisal in English. London, UK: Palgrave Macmillan. 
[28] Martin, J. R., and Rose, D. (2003). Working with discourse: Meaning beyond theclause. London: Continuum.

[29] Mey, J. (1993). Pragmatics. Oxford: Basil Blackwell.

[30] Olshtain, E., and A. D. Cohen. (1983). Apology: A Speech Act Set. In N. Wolfson and E. Judd (Eds.), Sociolinguistics and Language Acquisition. Rowley, MA: Newbury House Publishers, Inc.

[31] Pham , T. M. T., \& Yeh, A. (2020). Politeness of Vietnamese Students in Writing Request Email in English: a Course-based and Socio-pragmatic Study. International Journal of Language and Literary Studies, 2(2), 109-128. https://doi.org/10.36892/ijlls.v2i2.20

[32] Rees-Miller, J (2000). Power, Severity, and Context in Disagreement. Journal of Pragmatics, 32, 1087-1111.

[33] Searle, J. R. (1976). A Classification of Illocutionary Acts. Language and Society, 5 (1), 1-23.

[34] Searle, J. R. (1969). Speech acts: An essay in the philosophy of language. Cambridge: Cambridge University Press.

[35] Sifianou, M. (1992). Politeness Phenomena in England and Greece. Oxford: Clarendon Press.

[36] Takahashi, T. and L. M. Beebe. (1993). Cross-linguistic Influence in the Speech Act of Correction. In G. Kasper, and S. Blum-Kulka (Eds.), Interlanguage Pragmatics. New York: Oxford University Press.

[37] White, P. R. R. (2015). Appraisal theory. In K. Tracy (Ed.), International encyclopedia of language and social interaction (pp. 1-7). Hoboken, U.S.A: Wiley-Blackwell.

[38] Wierzbicka, A. (1991). Cross-Cultural Pragmatics: The Semantics of Human Interaction. Berlin/New York: Mouton de Gruyter.

[39] _. (1985). Different Cultures, Different Languages, Different Speech Acts. Journal of Pragmatics, 9, 145-79.

[40] Yu, M. (1999). Universalistic and culture-specific perspectives on variation in the acquisition of pragmatic competence in a second language. Pragmatics, 9, 281-312.

[41] Yule, G. (1996). Pragmatics. Oxford University Press. 
TASK

Appendix I

Discourse Completion Test

You are expected to express disagreement in the ten scenarios below. Please write down what you would say in real life situations.

Scenario 1: While you were doing shopping with your friend, he/she tries a pair of sneakers that you find unfashionable.

Scenario 2: For the first time in almost a week, good weather conditions have prevailed on your city today and you think you should profit from it and go to the beach with your friend. However, your friend says: "I think we should go watch a movie."

Scenario 3: One of your classmates claims that the Republic of Ireland is a constituent country of the UK.

Scenario 4: During a break at college, a classmate you are not familiar with says: "I think having a boyfriend or a girlfriend at college may have side effects on students' studies."

Scenario 5: While you are at computer shop helping your friend pick a new laptop, the salesperson intervenes and starts talking about the good qualities of a specific brand, which you think is not true.

Scenario 6: You decided to go camping this weekend with your friend. When your father heard about the plan, he refused because bad weather conditions are expected this weekend

Scenario 7:You are in the car with your teacher who is driving to the airport to meet a group of foreign students and teachers. While driving, the teacher reaches a traffic light and says "I guess we should turn left". You know very well the way to the airport and you know that it is still too far.

Scenario 8: You have a meeting with your supervisor whom you have known for a long time and who is friendly with you. The meeting is scheduled at 2 o'clock. You arrive at 2 and you find that your teacher is really angry and he claims that you are one hour late.

Scenario 9: By the end of the semester, you are required to hand a paper on a topic that you choose and discuss with your teacher. You have found a topic that you think is interesting. Your teacher suggests another topic instead of yours.

Scenario 10: The day you submit your term paper your teacher accuses you of plagiarism.

\section{Appendix II}

\section{Hedges and Boosters}

\begin{tabular}{|c|c|}
\hline \multicolumn{1}{|c|}{ Hedges } & \multicolumn{1}{c|}{ Boosters } \\
\hline Could-would -maybe- may -seem- & Think-thought-guess-believe-totally- \\
sound-probably- 'If-clauses'- passive & honestly-completely-entirely-hardly- \\
form-for a little while- a little- a little bit- & fairly certain-actually- definitely (not)- \\
kind of-please-I'm not sure-I must have & clearly -really-certainly-should-(pretty) \\
been mistaken. & sure- will-won't- have to-must- assure - \\
& a lot more. \\
\hline
\end{tabular}

